\title{
The prevalence of deep vein thrombosis in a cohort of patients with spinal cord injury following the Pakistan earthquake of October 2005
}

\author{
MFA Rathore ${ }^{1}$, S Hanif ${ }^{1}$, PW New ${ }^{2,3}$, AW Butt ${ }^{1}, \mathrm{MH}$ Aasi ${ }^{1}$ and S-U Khan ${ }^{4}$ \\ ${ }^{1}$ Spinal Rehabilitation Unit, Armed Forces Institute of Rehabilitation Medicine, Rawalpindi, Pakistan; ${ }^{2}$ Head, Spinal Rehabilitation \\ Unit, Caulfield General Medical Centre, Caulfield, Victoria, Australia; ${ }^{3}$ Departments of Medicine and Epidemiology \& Preventive \\ Medicine, Monash University, Melbourne, Victoria, Australia and ${ }^{4}$ Neurosurgical Ward, Holy family Hospital, Rawalpindi, Pakistan
}

\begin{abstract}
Study design: Prospective observational study.
Objectives: To assess the prevalence of symptomatic deep vein thrombosis (DVT) in earthquake survivors with spinal cord injury $(\mathrm{SCl})$.

Settings: Rawalpindi, Pakistan, in the months after the October 2005 earthquake.

Methods: Earthquake survivors $(n=187)$ with acute SCl were enrolled after verbal informed consent. Information on mechanism of injury, mode of evacuation, associated injuries was gathered, and a detailed clinical and radiological assessment was performed. They were followed for 10 weeks for clinical signs and symptoms suggestive of DVT. Case with clinical suspicion of a DVT underwent a duplex scan of both legs to confirm the diagnosis. The influence of age, gender, American Spinal Injury Association (ASIA) grade and lower limb fractures on occurrence of DVT was determined.

Results: There were 80 men and 107 women with a mean age of $28.3 \pm 12.4$ years. Seventeen patients were clinically suspected to have a DVT and ultrasound was positive in nine (4.8\%). There was no influence of age $(P=0.4)$, gender $(P=0.4)$, ASIA grade $(P=0.1)$ or presence of a lower limb fracture $(P=0.6)$ on the occurrence of a DVT.

Conclusion: This study adds further evidence to support the belief that the incidence of DVT in Southeast Asian patients with an $\mathrm{SCl}$ is lower than the reported incidence in the West. It may not be necessary to apply the recommendations for DVT prophylaxis in Caucasians with $\mathrm{SCl}$ to other groups, including Southeast Asians.
\end{abstract}

Spinal Cord (2008) 46, 523-526; doi:10.1038/sj.sc.3102170; published online 29 January 2008

Keywords: deep vein thrombosis; thromboembolism; spinal cord injury; earthquake; disasters; Pakistan

\section{Introduction}

Deep vein thrombosis (DVT) is defined as the interruption of blood flow through the deep veins due to the formation of a thrombus or clot, typically occurring after immobilization, surgery or trauma, but also occurring in individuals with no obvious risk factors. ${ }^{1}$ In Western populations, the incidence of DVT is 1-2 people per 1000 annually. $^{2}$ In comparison, the incidence of DVT in Asian population is believed to be lower, with an incidence of $1.3-6.1 \% .^{3-6}$ Because of the perceived lower risk for DVT compared to Western populations, the routine use of thromboprophylaxis in patients undergoing major surgical procedures is not an established practice in Pakistan. ${ }^{6}$ Spinal cord injury (SCI) is a strong risk factor for the development of venous

Correspondence: Dr MFA Rathore, Spinal Rehabilitation Unit, Armed Forces Institute of Rehabilitation Medicine, Abid Majeed Road, Rawalpindi 46000, Pakistan.

E-mail: farooqrathore@gmail.com

Received 2 July 2007; revised 2 December 2007; accepted 21 December 2007; published online 29 January 2008 thromboembolism. ${ }^{7}$ The prevalence of DVT following acute SCI in Western populations ranges from 5.4 to $28 \%$ with thromboprophylaxis. ${ }^{8-10}$

The earthquake that struck Pakistan on the 8th October 2005 was a devastating tragedy that left 73000 dead and 126000 injured. Owing to the absence of a national trauma registry, an accurate assessment of the total number of cases of SCI was difficult to determine, but the estimates range from 650 to 750 . Because of the unprecedented number of patients with acute SCI and the challenges to the health-care system to manage so many cases, adequate thromboprophylaxis was not available for most SCI patients. This provided an opportunity to study the prevalence of DVT in this highrisk group. A literature search did not identify previous research on either the prevalence of DVT in Southeast Asians with an acute SCI or the prevalence of DVT in earthquake victims with SCI. The aim of this study was to determine the prevalence of symptomatic DVT in a sample of acute SCI survivors of the October 2005 earthquake. 


\section{Methods}

Patient selection

A prospective observational study was conducted in 187 survivors of the 8th October earthquake with an acute SCI. All patients previously lived in the northern mountain region of Pakistan, which was the most severely struck by the earthquake. The majority of these patients belonged to the lower socioeconomic group. Typically, they resided high up the mountain and consumed maze as their staple diet. These patients were admitted between 15th October 2005 and 15th January 2006 to the following three centers:

(1) Spinal Rehabilitation Unit, Armed Forces Institute of Rehabilitation Medicine (AFIRM), Rawalpindi

(2) Paraplegic Centre, District Head Quarters (DHQ) Hospital, Rawalpindi

(3) Neurosurgical Ward, Holy Family Hospital (HFH), Rawalpindi

The diagnosis of SCI was based on the clinical examination findings of the neurosurgeon or rehabilitation medicine specialist. All patients had X-rays performed, and magnetic resonance imaging was available in 108 patients $(57.7 \%)$.

At the time of admission, a detailed evaluation of the patient was conducted. This included a comprehensive history that identified problems related to their SCI, features suggestive of DVT, other injuries, risk factors for DVT and any history of previous DVT. The severity of the SCI was determined by American Spinal Injury Association (ASIA) classification. ${ }^{11}$ Although exact data are not available only a few patients (approximately 10-12\%) received thromboprophylaxis in the form of compression stockings and unfractionated or low molecular weight heparin.

As the earthquake overwhelmed the available medical resources, priority was given to emergency treatment. It was not possible, therefore, to prospectively screen all patients with duplex ultrasound scanning. A pragmatic approach was therefore taken to the diagnosis of DVT. Patients were observed for clinical signs and symptoms suggestive of DVT (swelling, pain, redness and tenderness, increased spasticity), with the awareness that clinical examination of asymptomatic high-risk patients for venous thrombus by the most experienced physicians has a sensitivity of 33\% and a specificity of $50 \% .{ }^{12}$ In cases where there was any clinical suspicion of DVT, a duplex ultrasound was performed at the affiliated radiology department to confirm or refute the diagnosis. An experienced radiologist using 7.5 or $10 \mathrm{MHz}$ linear transducer probes performed duplex ultrasonography on both legs. Veins were studied from groin to ankle, and the presence of DVT was declared on non-compressibility or visualization of an intraluminal thrombus. In cases where duplex ultrasound was inconclusive, the scan was repeated after 1 week.

The confirmed cases of DVT were treated with bolus dose of $10000 \mathrm{IU}$ of unfractionated heparin, followed by intravenous infusion of unfractionated heparin $\left(1000 \mathrm{IU} \mathrm{h}^{-1}\right)$. Oral warfarin was commenced for 3 months. The monitoring of the therapeutic level of heparin was performed using activated thromboplastin time and that of warfarin by international normalized ratio. ${ }^{13}$

Participants gave verbal informed consent to participate in this study. In cases of children under 16 years, consent was obtained from their parent or guardian.

\section{Statistical analysis}

Data were analyzed using SPSS V 11. Descriptive statistics were used to calculate mean age, distribution of patients according to ASIA classification, surgical treatments and the number of patients developing DVT. The $\chi^{2}$ test was used to examine the relationship between the occurrence of DVT and gender, ASIA grade and presence of a lower limb fracture. $P$-values of 0.05 or less were considered statistically significant.

\section{Results}

The study group of 187 patients had a mean age of $28.3 \pm 12.4$ years (range $3-75$ years). There were 107 (57.2\%) female patients (mean age: $26.5 \pm 11.9$ years) and $80(42.8 \%)$ male patients (mean age: $30.75 \pm 12.8$ years). At the time of admission, 86 (46\%) patients had incomplete paraplegia, 81 (43.3\%) had complete paraplegia, 9 (4.8\%) had incomplete tetraplegia and 11 (5.9\%) had no deficit (ASIA-E). One hundred and forty patients (75\%) had surgery for spinal fixation. There was no family history or prior history of DVT in any patient. Those receiving heparin for thromboprophylaxis did not have any bleeding complications.

There were 17 patients who were clinically suspected of having a DVT and underwent a duplex ultrasound of lower limbs. DVT was confirmed in nine patients (4.8\%). There was no significant difference in the prevalence of DVT between male patients $(5 / 80 ; 6.2 \%)$ and female patients $(4 / 107 ; 3.7 \%)$ $\left(\chi_{1}^{2}=0.6 ; P=0.4\right)$ (Table 1$)$.

There was no influence of age $(P=0.4)$, ASIA grade $(P=0.1)$ or the presence of a lower limb fracture $(P=0.6)$ on the occurrence of DVT in SCI patients.

None of the patients who developed a DVT had received thromboprophylaxis. No patient with a duplex-confirmed DVT developed signs and symptoms suggestive of pulmonary embolism. The DVT resolved successfully in all patients with anticoagulation as documented by a negative repeat Doppler ultrasound performed after 4 weeks.

\section{Discussion}

The epidemiology of this cohort of patients has previously been reported. ${ }^{14}$ Patients with an SCI are traditionally felt to be at a high risk for developing DVT. 4,6,15 The importance of DVT is in the possibility of pulmonary embolism, which may prove fatal, and chronic venous insufficiency in the long term.

The incidence of DVT in acute SCI patients of Asian origin is not known, although the incidence of DVT is generally considered to be low in Asian populations..$^{3,5,15-17}$ Studies in Pakistan to asses the frequency of DVT in high-risk surgical 


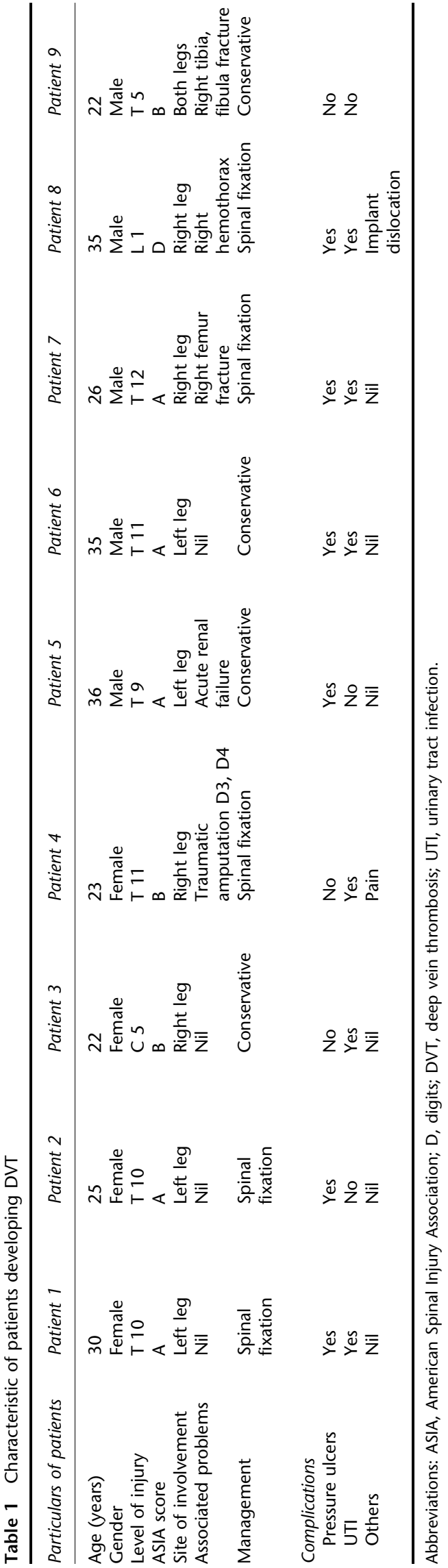

patients without thromboprophylaxis revealed an incidence ranging from 0 to $12.8 \% .^{6,18,19}$ Similarly, studies conducted in neighboring India to asses the risk of DVT in patients undergoing hip and knee arthroplasties reported the incidence of DVT to be $6.1 \%$ (Bagaria et al. ${ }^{4}$ ) and $2.8 \%$ (Jain et $a .^{20}$ ), respectively, which is significantly lower than the incidence in the West. ${ }^{8,9}$

In our study, DVT was found to be more common in patients who had complete SCI and were immobilized for a longer period of time than the patients having incomplete injury or no neurological deficit and who were mobilized earlier. A recent report of complications in a different cohort of 194 SCI earthquake survivors found that only 3 patients (2\%) developed DVT, with one dieing of a pulmonary embolism. ${ }^{21}$ Although the authors did not report on the use of DVT prophylaxis, it is unlikely, given the circumstances, that many in their sample would have received thromboprophylaxis. There are many similarities in this report with our patients, and together these findings provide further evidence that the prevalence of DVT is low in Southeast Asians, even without thromboprophylaxis.

Duplex ultrasound scan was chosen as a diagnostic tool for DVT in this study because during the past two decades invasive diagnostic procedures for DVT diagnosis have been gradually replaced by non-invasive methods. ${ }^{22}$ Duplex ultrasound is a cost-effective tool for DVT surveillance in individuals with acute traumatic SCI. ${ }^{23}$ The diagnostic sensitivity and specificity of duplex ultrasound for detection of DVT has been well established in the past decade. ${ }^{2,7,24,25}$

\section{Possible explanations of low incidence of DVT}

There are several explanations for the low incidence of DVT observed in this study group despite being high risk and not receiving adequate thromboprophylaxis. The most likely is that genetic factors may play a role. These include activated protein $\mathrm{C}$ resistance, an increase in the inhibitor of plasminogen activator-1, hyper-homocysteinemia or a lower prevalence of factor $\mathrm{V}$ leiden mutation, which is more common in the western population. ${ }^{4,5,26}$ Obesity and heart failure are acquired traits that are thought to be risk factors for development of DVT and have been found to be less prevalent in Asians. ${ }^{4,5}$ Both of these factors were absent in our study group. Another possible explanation could be that soon/immediately after admission, patients received three times a day passive range of motion exercises and massage of lower limbs. This was achievable due to the availability of a large number of caretakers, but there is no scientific evidence for this benefit. Another alternative explanation might be dietary factors. There is a need for further research to explore the reasons for the reduced prevalence of DVT in Southeast Asians.

\section{Limitations of the study}

There are two limitations of this study. First, duplex ultrasound is an operator-dependent technique and in our study a single operator did not perform all the tests. Therefore, there is a possibility of interobserver differences while interpreting the results of scan. Second, all DVTs are not symptomatic. In this study, duplex scan was carried out 
only on clinical suspicion; therefore, there is a possibility that asymptomatic DVTs might have been missed and the actual prevalence would have been higher if all patients were scanned.

\section{Conclusions}

This is the first study, to our knowledge, on DVT after acute SCI due to an earthquake. It suggests that the prevalence of symptomatic DVT is quite low in a South Asian population. This is not, however, generalizable to Caucasian populations.

Results from this study suggest that it may not be advisable to apply the Western practice of thromboprophylaxis to all SCI patients in Southeast Asians and that further large-scale prospective trials that screen all patients are needed.

\section{Acknowledgements}

No financial support was received for this study.

\section{Conflict of interest}

None.

\section{Disclosure}

(1) This article is based on a paper titled 'Frequency of DVT in earthquake victims of spinal cord injury - a multicentre study,' presented at International Conference on Disaster Management held at Convention Center Islamabad, Pakistan (12-14th January 2007).

(2) Part of these data appeared in the article 'Rathore MFA, Rashid P, Butt AW, Malik AA, Gill ZA, Haig AJ. Epidemiology of spinal cord injuries in the 2005 Pakistan earthquake. Spinal Cord 2007; 45: 658-663.'

\section{References}

1 Cann AJ. Cardiovascular diseases. In: Kumar P, Clark M (eds). Clinical Medicine, 5th edn. WB Saunders: UK, 2002, pp 701-832.

2 White RH. The epidemiology of venous thromboembolism. Circulation 2003; 107 (23 Suppl 1): 14-18.

3 Lee HM, Suk KS, Moon SH, Kim DJ, Wang JM, Kim NH. Deep vein thrombosis after major spinal surgery: incidence in an East Asian population. Spine 2000; 25: 1827-1830.

4 Bagaria V, Modi N, Panghate A, Vaidya S. Incidence and risk factors for development of venous thromboembolism in Indian patients undergoing major orthopedic surgery: results of a prospective study. Postgrad Med J 2006; 82: 136-139.

5 Kalstky AL, Armstrong MA, Poggi J. Risk of pulmonary embolism and/or deep vein thrombosis in Asian Americans. Am J Cardiol 2000; 85: 1334-1337.

6 Aziz I. Frequency of post operative deep vein thrombosis in highrisk surgical patients. J Coll Physicians Surg Pak 2005; 15: 299-301.
7 Blann AD, Lip JYH. Venous thromboembolism. BMJ 2006; 332: 215-219.

8 Aito S, Pieri A, D'Andrea M, Marcelli F, Cominelli E. Primary prevention of deep venous thrombosis and pulmonary embolism in acute spinal cord injured patients. Spinal Cord 2002; 40: 300-303.

9 Jones T, Ugalde V, Franks P, Zhou H, White RH. Venous thromboembolism after spinal cord injury: incidence, time course and associated risk factors in 16240 adults and children. Arch Phys Med Rehabil 2005; 86: 2240-2247.

10 Anson CA, Shepherd C. Incidence of secondary complications in spinal cord injury. Int J Rehabil Res 1996; 19: 55-66.

11 American Spinal Injury Association. International Standards for Neurological Classification of Spinal Cord Injury. ASIA: Chicago, 2002.

12 Alpert JS, Dalen JE. Epidemiology and natural history of venous thromboembolism. Prog Cardiovasc Dis 1994; 36: 417-422.

13 Rosenberg RD, Aird WC. Vascular-bed-specific hemostasis and hypercoagulable states. N Engl J Med 1999; 340: 1555-1564.

14 Rathore MFA, Rashid P, Butt AW, Malik AA, Gill ZA, Haig AJ. Epidemiology of spinal cord injuries in the 2005 Pakistan earthquake. Spinal Cord 2007; 45: 658-663.

15 Anderson FA, Spencer FA. Risk factors for venous thromboembolism. Circulation 2003; 107 (Suppl 1): 16-19.

16 Ho YN, Seow-Choen F, Leong A, Eu KW, Nyam D, Teoh MK. Randomized, controlled trial of low molecular weight heparin vs no deep vein thrombosis prophylaxis for major colon and rectal surgery in Asian patients. Dis Colon Rectum 1999; 42: 196-202; discussion 202.

17 Kumar K, Tang KK, Thomas J, Chumpon C. Is post operative deep vein thrombosis problem in neurosurgical patients with brain tumours in Singapore? Singapore Med J 2002; 43: 345-349.

18 Mirza W, Ashraf S, Fawad A. Role of routine thromboprophylaxis in patients under going major surgery. Pak J Med Res 2005; 44: 4-11.

19 Afzal M, Rafi M, Akbar M, Shahid M. Diagnosis of deep vein thrombosis in the leg using 1125 fibrinogen up take test: a preliminary study. Pak J Surg 1995; 11: 211-212.

20 Jain V, Dhaon BK, Jaiswal A, Nigam V, Singla J. Deep vein thrombosis after total hip and knee arthroplasty in Indian patients. Postgrad Med J 2004; 80: 729-731.

21 Tauqir SF, Mirza S, Gul S, Ghaffar H, Zafar A. Complications in patients with spinal cord injuries sustained in an earthquake in Northern Pakistan. J Spinal Cord Med 2007; 30: 313-317.

22 Kraaijenhagen RA, Piovella F, Bernardi E, Verlato F, Beckers EAM, Koopman MMW et al. Simplification of the diagnostic management of suspected deep vein thrombosis. Arch Intern Med 2002; 162: 907-911.

23 Kadyan V, Clinchot DM, Colachis SC. Cost-effectiveness of duplex ultrasound surveillance in spinal cord injury. Am J Phys Med Rehabil 2004; 83: 191-197.

24 Ko PS, Chan WF, Siu TH, Cheng A, Lee OB, Lam JJ. Duplex ultrasonography after total hip or knee arthroplasty. Int Orthop 2003; 27: 168-171.

25 Naz R, Naz S, Mehboob M, Achakzai A, Khalid GH. Diagnostic yield of color Doppler ultrasonography in deep vein thrombosis. J Coll Physicians Surg Pak 2005; 15: 276-279.

26 Aito S, Abbate R, Marcucci R, Cominelli E. Endogenous risk factors for deep-vein thrombosis in patients with acute spinal cord injuries. Spinal Cord 2007; 40: 627-631. 